\title{
Original article (short paper) \\ Comparison of different ways of expressing creatine kinase concentration of soccer players during a competitive season
}

\author{
Daniel Barbosa Coelho \\ Universidade de Ouro Preto, Ouro Preto, MG, Brasil \\ Christian Emmanuel Torres Cabido \\ Universidade Federal do Maranhão, São Luís, MA, Brasil \\ Victor Augusto Lemos Ciminelli \\ Universidade Federal de Ouro Preto, Ouro Preto, MG, Brasil \\ Leonardo Gomes Martins Coelho \\ Universidade Federal de Minas Gerais, Belo Horizonte, MG, Brasil \\ Centro Federal de Educação Tecnológica de Minas Gerais, Ouro Preto, MG, Brasil \\ Lenice Kapes Becker \\ Emerson Cruz de Oliveira \\ Universidade Federal de Ouro Preto, Ouro Preto, MG, Brasil \\ Emerson Rodrigues Pereira \\ Universidade Federal de Minas Gerais, Belo Horizonte, MG, Brasil \\ Centro Educacional de Sete Lagoas, Sete Lagoas, MT, Brasil \\ João Carlos Bouzas Marins \\ Universidade Federal da Viçosa, Viçosa, MG, Brasil \\ Emerson Silami Garcia \\ Universidade Federal do Maranhão, Maranhão, MA, Brasil
}

\begin{abstract}
The aim of this study was to analyze the responses of creatine kinase [CK] expressed in different forms to the training load of professional soccer players during a competitive season. Twelve players (age, $24 \pm 4$ years) participated in the study. [CK] was analyzed before the pre-season (Pre), after the pre-season (Post), and in the competitive mesocycles (M1, M2, and M3). Results showed [CK] in the Pre, Post, M1, M2, and M3 phases in absolute values $(181.3 \pm 58.7,416.4$ $\pm 155.7,526.4 \pm 268.0,403.8 \pm 137.0$, and $442.5 \pm 212.3 \mathrm{U} / \mathrm{L}$, respectively), relative values $(16.3 \pm 4.6,39.5 \pm 19.1,47.8$ $\pm 20.1,37.5 \pm 14.2,40.1 \pm 17.4 \% \mathrm{CK}_{\text {máx }}$, respectively), and values relative to the variation delta $(19.9 \pm 3.6,48.1 \pm 26.5$, $57.0 \pm 23.2,45.1 \pm 17.7$, and $48.3 \pm 22.0 \% \Delta \mathrm{CK}_{\text {máx }}$, respectively). [CK] was lower only during the Pre phase compared to the other phases $(p<0.05)$. [CK] was expressed as $\% \mathrm{CK}_{\text {máx }}$ or $\% \Delta \mathrm{CK}_{\text {máx }}$ may be more specific to monitor training. In addition, the individualization of this biomarker optimizes the athletes' performance as muscle injuries can be prevented.
\end{abstract}

Keywords: physical exertion, training, performance

\section{Introduction}

Competitive soccer requires great physical effort, including jumps, ball disputes, sprints, braking, accelerations, and changes of direction ${ }^{1,2}$. Moreover, a competitive season is marked by a large number of high-intensity games ${ }^{3}$ and with more than one competition occurring simultaneously; therefore, the time available for athletes to recover is not always sufficient ${ }^{4}$.
Periods of intense and lengthy workouts can trigger a process called overtraining that decreases sportive performance ${ }^{5}$ and leads to the athlete's temporary (burn-out) or permanent (drop-out) retirement from the sport ${ }^{6}$. Thus, monitoring the training status of athletes to identify whether they have already recovered before being subjected to a new stimulus is of fundamental importance for gaining adequate control of the training load ${ }^{7,8}$. 
Taking this into consideration, several physiological indicators of physical stress have been investigated, namely creatine kinase $(\mathrm{CK})^{4,8-13}$. Specifically, CK is an energy metabolism-related cytoplasmic enzyme that, when released into the extracellular medium, is indicative of muscle microtrauma ${ }^{3,4,12,14,15}$. An elevation of serum $\mathrm{CK}$ level $\left[\mathrm{CK}_{\text {serum }}\right]$ is usually observed one to four days after physical activity ${ }^{16-19}$ and is an indicator of the stress imposed on the skeletal muscle following exercise ${ }^{13,20,21}$. Recently, CK has also been used as a monitoring marker of training load ${ }^{22-24}$, especially in soccer ${ }^{5,25}$, since its measurement can be performed quickly and conveniently.

However, the CK response to exercise shows great individual variability ${ }^{9,26,27}$ because it is influenced by personal factors, such as gender, race, muscle mass, training status ${ }^{23}$, and genetic predisposition ${ }^{28}$. Therefore, the same training stimulus can cause different individuals to be classified as having a high or low response to increased $\left[\mathrm{CK}_{\text {serum }}\right]$. However, little is known about the response of $\mathrm{CK}$ in the reality of Brazilian soccer ${ }^{3,4,13}$, a collective sport with an intermittent, high-intensity pattern and short periods of preparation and recovery in which more than one competition may occur simultaneously.

Therefore, the aim of this study was to analyze the responses of $\left[\mathrm{CK}_{\text {serum }}\right]$ expressed in different forms to the training load of professional soccer players during a competitive season.

\section{Methods}

This study was approved by the ethics in research committee of the Federal University of Minas Gerais (ETIC-291/09) and complied with all the norms set by the National Health Council (Res. 196/96) involving human research. Written informed consent was obtained from the volunteers prior to their participation in the study after they were given the opportunity to raise any questions or concerns they may have had.

\section{Participants}

Professional players from a club in the first division of the Brazilian soccer that participates in the national and international competitions organized by the Brazilian Football Confederation and the South American Football Confederation comprised the sample for this study.

All athletes were monitored during the months of the state and South American championships, which occurred concurrently between January and April 2010, for 18 games in total. Ultimately, twelve players participated in this study (age, 24 \pm 4 years; height, $181.1 \pm 7.0 \mathrm{~cm}$; weight, $77.6 \pm 3.8 \mathrm{~kg}$; body fat, $9.1 \pm 1.3 \%$; and $\left.\mathrm{VO}_{2 \text { máx }}, 660 \pm 4.5 \mathrm{~mL} \cdot \mathrm{kg}^{-1} \cdot \mathrm{min}^{-1}\right)$. The inclusion criteria of the athletes were as follows: participation in all the CK collections described below and participation in $>60 \%$ of all training activities. The athletes who did not fulfill the above criteria, or who suffered any injury during the study, were not included. A total of 21 athletes were eligible when the study began.

\section{Procedures}

The climatic conditions monitored during the training phase in this study were: $24.65 \pm 3^{\circ} \mathrm{C}$ and $61 \pm 7 \%$ relative humidity.

$\left[\mathrm{CK}_{\text {serum }}\right]$ was determined during presentation of the players prior to their first training session; this was designated as the concentration at the beginning of the pre-season (Pre). At the time of this sample collection, the athletes were returning from vacation and thus, had not performed any previous systematic physical activity.

The $\mathrm{HR}_{\text {máx }}$ was determined by the highest value found in one of two situations: 1) specific field test (Yoyo Endurance Test Level II) to determine the players' maximal aerobic capacities, and 2) training sessions. ${ }^{29}$ During the pre-season, CK samples were collected on the $4^{\text {th }}, 10^{\text {th }}$, and $15^{\text {th }}$ day. The average of these values corresponded to the time after pre-season (Post). The blood collections in pre-season were conducted at least 14 hours following the last training session.

The competitive period was divided into three mesocycles, each representing a total of approximately 30 days of training. The average of the CK measurements after each game within a mesocycle was then defined as the representative value for that specific mesocycle; the first, second, and third mesocycles were designated M1, M2, and M3, respectively. During this period, CK samples were collected 32-36 hours after the games from those players who participated in at least 75 minutes of that game. Blood samples were analyzed for CK immediately after collection.

During the competitive phase, the levels were monitored after the games since higher concentrations of CK were expected at these times as a result of post-game stress. Moreover, this was the average period of the presentation of the players after the games. Since the samples were collected 2-3 times per mesocycle, which was the number of games used as inclusion criteria in the study, the mean values of these measurements represented the mesocycle monitoring. All of the samples were collected in the morning prior to the day's training session.

Players who did not play in a sufficient number of games were excluded from the study. As the average number of athletes in a team throughout a season is 30 , it was not possible to have a control group of players that only trained and did not play. CK monitoring was performed in three ways: 1) absolute values, 2) values relative to the maximum concentration of CK observed throughout the season in the athlete $\left(\% \mathrm{CK}_{\text {max }}\right)$, and 3$)$ values relative to the maximum variation delta in $\mathrm{CK}$ concentration observed during the season $\left(\% \Delta \mathrm{CK}_{\text {maxx }}\right)$. To calculate this last form of expression, the resting CK (Pre) value was subtracted from the exercise $\mathrm{CK}$ value, and this was then divided by the maximum delta of variation $\left[\left(\mathrm{CK}_{\text {monitored }}-\mathrm{CK}_{\text {pre }}\right) / \Delta \mathrm{CK}_{\text {máx }}\right] \times 100$.

After the site was cleaned with $70 \%$ ethanol, a puncture was performed using an automatic lancet and the blood was drained into a heparinized capillary tube (Cat No. 955053202 Reflotron $\AA$; Boehringer Mannheim, USA). The blood $(32 \mu \mathrm{L})$ was immediately pipetted onto a CK test strip (Cat No. 1126695 Reflotron $\AA$ ) and placed in the Reflotron Analyser ${ }^{\circledR}$ (Boehringer Mannheim), as performed in previous studies ${ }^{3,30}$. The monitoring of the training load during the microcycles was performed via heart rate (HR) measurement represented in absolute values, the percentage of maximum heart rate $\left(\% \mathrm{HR}_{\text {máx }}\right)$, and the measurement of the 
distance covered in the training sessions. To measure and record HR, a set of heart monitors was used (Polar Electro Oy®; Polar Team System, Finland). To assess the distance covered, a portable GPS device (Forerunner® 405; Garmin, USA) was used; the sum of the monitored values is presented.

\section{Statistical analysis}

Initially, the Kolmogorov-Smirnov test was applied to verify the normality of the data. Since all data showed normality (absolute CK values, $p=.60 ; \% \mathrm{CK}_{\text {máx },} p=.204 \% \Delta \mathrm{CK}_{\text {máx }} p=.093$ ), parametric statistics were used. To compare the different phases, an analysis of variance with one-factor repeated-measures (one-way ANOVA with repeated measures) and the post-hoc Bonferroni test were used when necessary. Values are showed as mean and standard deviation. Furthermore, the statistic power $(\omega)$ of analysis of variance and Partial Eta Squared $\left(\eta_{p}^{2}\right)$ to demonstrate the magnitude of the differences between each measure $(\text { small }<.01 \text {, mean }=.06 \text {, extensive }>.14)^{31}$ were calculated. The significance level was set at $\alpha<.05$. The Statistical Package for the Social Sciences for Windows 14.0 (SPSS Inc., Chicago, IL, USA) was used to analyze the data.

\section{Results}

Table 1 shows the characteristics of the monitored period.

The one-way ANOVA with repeated measures for absolute values CK $[\mathrm{U} / \mathrm{L}]\left(F_{4,44}=8,93 ; p<0,001 ; \eta_{p}^{2}=0,45 ; \omega=0,99\right)$ showed significant differences between Pre and other measures (Post, $p=0.001 ; \mathrm{M} 1, p=0.012 ; \mathrm{M} 2 ; p=0.004 ; \mathrm{M} 3, p=0,015$ ) (Table 2). No significant differences were found in the remaining comparisons $(p>.05)$.

Similarly, the one-way ANOVA with repeated measures for percentages of $\mathrm{CK}_{\text {máx }}\left[\% \mathrm{CK}_{\text {máx }}\right]\left(F_{4,44}=8,37 ; p<.001 ; \eta_{p}^{2}\right.$ $=.43 ; \omega=.98)$ showed only differences between Pre and other measures (Post, $p=.005$; M1, $p=.004 ; \mathrm{M} 2 ; \mathrm{p}=.004 ; \mathrm{M} 3, p$ $=.006$ ) (Table 3 ). No significant differences were found in the remaining comparisons $(p>.05)$.

For percentages of delta $\mathrm{CK}$ variation $\left[\% \Delta \mathrm{CK}_{\text {máx }}\right]$ analysis, the one-way ANOVA with repeated measures $\left(F_{4,44}=7,88 ; p\right.$ $\left.<.001 ; \eta_{p}^{2}=.41 ; \omega=.99\right)$ indicated only differences between Pre and other measures (Post, $p=.009$; M1, $p=.003$; M2; $p=.004$; M3, $p=.006$ ) (Table 4). No significant differences were found in the remaining comparisons $(p>.05)$.

Table 1. Description of the elapsed time of each type of training, and the distance and intensity $\left(\% \mathrm{HR}_{\text {max }}\right)$ for each phase of training (training mesocycle). Absolute and relative values (\%) for each phase are shown.

\begin{tabular}{|c|c|c|c|c|c|c|c|c|}
\hline \multirow[t]{2}{*}{ Microcycles } & \multicolumn{2}{|c|}{ Post } & \multicolumn{2}{|c|}{ M1 } & \multicolumn{2}{|c|}{ M2 } & \multicolumn{2}{|c|}{ M3 } \\
\hline & Absolut & $\%$ & Absolut & $\%$ & Absolut & $\%$ & Absolut & $\%$ \\
\hline Tr.G. Des. (min) & 300 & 19.92 & 230 & 9.64 & 110 & 5.41 & 180 & 6.5 \\
\hline Tr. G. Rec. (min) & 290 & 19.26 & 400 & 16.77 & 390 & 19.16 & 535 & 19.31 \\
\hline Tr. E. Sim. (min) & 450 & 29.88 & 520 & 21.8 & 405 & 19.9 & 630 & 22.74 \\
\hline Tr. E.Compl. (min) & 195 & 12.95 & 290 & 12.16 & 330 & 16.22 & 355 & 12.82 \\
\hline Tr. E.Compe. (min) & 270 & 17.93 & 945 & 39.62 & 800 & 39.31 & 1070 & 38.63 \\
\hline$\Sigma$ micr. (min) & 1506 & 100 & 2385 & 100 & 2035 & 100 & 2770 & 100 \\
\hline Dis. Per. (km) & 82.8 & - & 146.7 & - & 126.2 & - & 198.8 & - \\
\hline $\mathrm{HR}\left(\% \mathrm{HR}_{\text {máx }}\right)$ & $76.1 \pm 5.2$ & - & $71.9 \pm 4.4$ & - & $70.7 \pm 3.5$ & - & $71.9 \pm 6.4$ & - \\
\hline
\end{tabular}

Classification of exercises according to Frisseli and Montovani ${ }^{27}$. Development general training (Tr.G. Dis.); Recovery general training (Tr. G. Rec); Simple Specific Training (Tr. E. Sim.); Complex specific training (Tr. E. Compl); Competitive specific training (Tr. E. Compe); Sum of the time in each micro-cycle ( $\Sigma$ micr.); Time after the pre-season (Post); Mesocycle 1 (M1); Mesocycle 2 (M2); Mesocycle 3 (M3), minutes (Min); Type of training (Tr.); Heart rate (HR); and percentage of maximum heart rate $\left(\% \mathrm{HR}_{\text {máx }}\right)$.

Table 2. Creatine kinase (CK) values of players during a competitive soccer season, expressed in absolute terms.

\begin{tabular}{ccccccccccccccccc}
\hline Phases/volun & V-1 & V-2 & V-3 & V-4 & V-5 & V-6 & V-7 & V-8 & V-9 & V-10 & V-11 & V-12 & X & SD & CV \\
\hline Pre & 110 & 207 & 180 & 199 & 186 & 265 & 212 & 102 & 158 & 137 & 292 & 128 & 181,3 & 58,7 & 32,4 \\
Post & 467 & 651 & 371 & 568 & 249 & 336 & 339 & 408 & 221 & 697 & 435 & 256 & $416,4^{*}$ & 155,7 & 37,4 \\
M1 & 861 & 273 & 206 & 700 & 764 & 725 & 955 & 395 & 390 & 205 & 565 & 280 & $526,4^{*}$ & 268 & 50,9 \\
M2 & 507 & 351 & 274 & 744 & 439 & 361 & 467 & 295 & 330 & 289 & 289 & 502 & $403,8^{*}$ & 137 & 33,9 \\
M3 & 779 & 476 & 270 & 706 & 362 & 394 & 836 & 325 & 229 & 318 & 370 & 246 & $442,5^{*}$ & 212,3 & 48 \\
\hline
\end{tabular}

Values are presented in an absolute values U/L (12 players), mean (X), standard deviation (SD), and coefficient of variation (CV). *Difference compared to the Pre phase $(p<0.05)$. Values at rest (Pre), after the pre-season (Post), and at the end of mesocycles 1 (M1), 2 (M2), and 3 (M3). 
Table 3. Creatine kinase (CK) expressed in values relative (\%) to the maximum concentration of CK-U/L during a competitive soccer season

\begin{tabular}{ccccccccccccccccc}
\hline Phase/volun & $\mathbf{V - 1}$ & $\mathbf{V - 2}$ & $\mathbf{V - 3}$ & $\mathbf{V - 4}$ & $\mathbf{V - 5}$ & $\mathbf{V - 6}$ & $\mathbf{V - 7}$ & $\mathbf{V - 8}$ & $\mathbf{V - 9}$ & $\mathbf{V - 1 0}$ & $\mathbf{V - 1 1}$ & $\mathbf{V - 1 2}$ & $\boldsymbol{X}$ & $\boldsymbol{S} \boldsymbol{D}$ & $\boldsymbol{C} \boldsymbol{V}$ \\
\hline Pre & 8,5 & 27 & 14,4 & 14 & 13,3 & 17,4 & 18,3 & 13,4 & 14,2 & 20,9 & 17,3 & 18 & 16,3 & 4,6 & 28,3 \\
Post & 35,9 & 85 & 29,7 & 40 & 17,8 & 22,1 & 29,2 & 53,6 & 19,9 & 49,8 & 55 & 36 & $39,5 *$ & 19,1 & 48,3 \\
M1 & 66,2 & 35,6 & 16,4 & 78,9 & 54,6 & 47,7 & 82,3 & 51,8 & 35,2 & 40,4 & 25,9 & 39,3 & $47,8^{*}$ & 20,1 & 42,1 \\
M2 & 39 & 45,8 & 21,9 & 52,4 & 31,4 & 23,7 & 40,2 & 38,7 & 29,7 & 20,6 & 36,5 & 70,5 & $37,5 *$ & 14,2 & 37,7 \\
M3 & 59,9 & 62,1 & 21,6 & 49,7 & 25,8 & 25,9 & 72,1 & 42,8 & 20,6 & 26,4 & 40,2 & 34,6 & $40,1 *$ & 17,4 & 43,4 \\
\hline
\end{tabular}

Values are presented (12 players) in relation to the percentage of the maximum concentration of CK (\% CK máx $)$ mean $(\mathrm{X})$, standard deviation (SD) and coefficient of variation (CV). *Difference compared to the Pre phase $(p<0.05)$. Values at rest (Pre), after the pre-season (Post), and at the end of mesocycles 1 (M1), 2 (M2), and 3 (M3).

Table 4. Creatine kinase (CK) expressed in values relative to the delta maximum variation in the concentration of $\mathrm{CK}_{(}\left(\% \Delta \mathrm{CK}_{\text {max }}\right)$ throughout a competitive soccer season

\begin{tabular}{cccccccccccccccc}
\hline Phase/volun & $\mathbf{V - 1}$ & $\mathbf{V - 2}$ & $\mathbf{V - 3}$ & $\mathbf{V - 4}$ & $\mathbf{V - 5}$ & $\mathbf{V - 6}$ & $\mathbf{V - 7}$ & $\mathbf{V - 8}$ & $\mathbf{V - 9}$ & $\mathbf{V}-\mathbf{1 0}$ & $\mathbf{V}-\mathbf{1 1}$ & $\mathbf{V}-\mathbf{1 2}$ & $\boldsymbol{X}$ & $\boldsymbol{S} \boldsymbol{D}$ & $\boldsymbol{C} \boldsymbol{V}$ \\
\hline Pre & 9,2 & 37 & 16,8 & 16,3 & 15,3 & 21,1 & 22,4 & 15,5 & 16,6 & 26,4 & 20,9 & 21,9 & 19,9 & 3,6 & 55,5 \\
Post & 39,2 & 117 & 34,6 & 46,5 & 20,5 & 26,8 & 35,7 & 61,9 & 23,2 & 62,9 & 66,6 & 43,9 & $48,1^{*}$ & 26,5 & 54,9 \\
M1 & 72,4 & 48,8 & 19,2 & 91,7 & 62,9 & 57,7 & 101 & 59,9 & 41 & 51 & 31,3 & 47,9 & $57,0^{*}$ & 23,2 & 40,7 \\
M2 & 42,6 & 62,7 & 25,6 & 60,9 & 36,2 & 28,7 & 49,2 & 44,7 & 34,6 & 26,1 & 44,2 & 86 & $45,1^{*}$ & 17,7 & 39,3 \\
M3 & 65,4 & 85,1 & 25,2 & 57,8 & 29,8 & 31,4 & 88,2 & 49,4 & 24,1 & 33,4 & 48,6 & 42,2 & $48,3 *$ & 22 & 45,5 \\
\hline
\end{tabular}

Values are presented (12 players) in relation to the percentage of the delta variation of the $\mathrm{CK}\left(\% \Delta \mathrm{CK}_{\operatorname{mix}}\right)$, mean $(\mathrm{X})$, standard deviation (SD) and coefficient of variation $(\mathrm{CV}){ }^{*}$ Difference compared to the Pre phase $(p<0.05)$. Values at rest (Pre), after the pre-season (Post) at the end of mesocycle 1 (M1), a the end of mesocycle 2 (M2) and at the end of mesocycle 3 (M3).

\section{Discussion}

The aim of this study was to analyze the responses of $\left[\mathrm{CK}_{\text {serum }}\right]$ expressed in different forms during a competitive soccer season. The main contributions of this study were presentation of the values of each athlete individually and of two more expressions $\left[\mathrm{CK}_{\text {serum }}\right]$ in addition to the absolute values. As observed (Tables 2-4), CK concentrations were higher in the Post, M1, M2, and M3 periods than in the Pre period, regardless of expression method. These results correspond to a response to a demand imposed by training loads and the competitive period, as expected. As the competitions began, there was a decrease in the general training load and an increase in the specific competitive training load. Despite this, there were no significant differences in serum CK concentrations. To explain this finding, we may speculate about a possible muscular adaptation to training.

Zoppi ${ }^{13}$ used CK as a parameter for chronic monitoring of 21 sub- 20 soccer players over five months of the Brazilian championship. CK concentrations were determined every month. The first determination was performed at the end of the pre-season and before the competitions and terminated when the team was disqualified from the championship. The authors found values of 350-400 U/L throughout the season, similar to those found in the present study; however, pre-competition values or the individual relativized values were not observed in this study. Moreover, the training load was also not shown. It should be emphasized that the players evaluated in the abovementioned study only participated in one competition during the study period, and not in two simultaneous competitions like the players in the present study.

Lazarim $^{4}$ evaluated 128 professional players at different times during the Brazilian soccer championship and found mean resting values of $493 \pm 315 \mathrm{U} / \mathrm{L}$. Although these values showed high variability, they were similar to our results and are values expected for active individuals, athletes, and particularly soccer players. In this same study, the authors performed a monthly evaluation of 29 players during the national championship, which lasted for five months. In this analysis, the values obtained were similar to those in the present study, but they varied between the evaluated months. Additionally, in the second month of the championship, high $\mathrm{CK}$ values were observed, which then normalized in the following months. Additionally, the authors did not report data relating to the training load throughout the championship.

To monitor the training status of rugby athletes and identify a possible state of overtraining, Coutts ${ }^{25}$ monitored a team of 18 players over a six-week preparation period. The team was divided into two groups; the second group performed the same training as the first group, but with greater volume and intensity. The authors found that the testosterone/cortisol ratio decreased over time (for both groups) and increased in the post-training period for the second group. The $\mathrm{VO}_{2 \text { max }}$ of athletes in the lower intensity group was higher in the post-training period, which indicates that the group that trained at a higher intensity had adaptation difficulties. CK concentration values increased steadily over the weeks and were higher in the higher intensity group, reaching values of $1,402 \pm 1,107 \mathrm{U} / \mathrm{L}$ in the sixth week, which were almost double the values of the normal training group. The values obtained in this study were higher than those obtained in the present study, which may be attributed to the fact that different sports were analyzed. The applicability of CK as a biochemical monitoring marker for training status was confirmed in that study; CK concentration responded to increase in volume and intensity of physical activity, as in the present study. 
Nunes $^{25}$ analyzed enzymatic, psychometric, and hematological parameters during a microcycle within a pre-season of professional soccer to determine which variable is more sensitive to training loads. Results showed that there was a significant increase in the CK and LDH enzymatic variables, as well as a reduction in hematological variables, erythrocytes, hemoglobin, and hematocrit in response to the evaluated training load. According to the authors, CK was the variable that best responded to the training load, whereas the other studied variables could be used as a complement while monitoring the acute effects of soccer-training load.

Overall, CK monitoring shows great individual variabili$\mathrm{ty}^{27}$, even values for individuals who perform similar training and the values of a group of athletes rarely show a normal distribution $^{27}$, which may compromise the interpretation of the mean data of a team, especially in sports like soccer. Thus, as in the case of other physiological variables used for monitoring physical activity, the presentation of individualized values that are relative to the maximum values CK data is of interest for establishing parameters for interpretation and intervention in the training period. Moreover, in a secondary analysis, we found that athletes with higher basal CK levels also presented with a higher $\mathrm{CK}_{\text {max }}(r=0.60, p<0.05$ - unpublished data). Thus, the use of the relative values of $\mathrm{CK}$, instead of absolute values, is an alternative method to interpret the $\mathrm{CK}$ responses to physical exertion on an individual basis.

Thus, by stipulating a maximum value of $\left[\mathrm{CK}_{\text {serum }}\right]$, we obtained the stress threshold that a player can reach. As a result, training can be conducted individually with a load compatible with each athlete's biomarkers, preserving those most vulnerable, thus preventing muscle injuries and optimizing the athletes' performance. The training of high-performance athletes should be based on the progress of evidence in sports science to improve the physical use and obtain the lowest possible organic exhaustion ${ }^{32}$.

As observed in the results, the coefficient of variation $(\mathrm{CV})$ of $\mathrm{CK}$ expressed as $\% \Delta \mathrm{CK}_{\text {max }}$ is higher than the other expressions of concentration. The $\mathrm{CV}$ is the mean divided by the standard deviation and indicates how the measure varies; in this case, the more this measure varies, the more individualized it should be. This aspect reveals that by using this data expression method, the variation between the individuals results increase, indicating a greater need to individually monitor each athlete's training.

With this goal, Lazarim ${ }^{4}$ established percentages to determine the $\mathrm{CK}$ concentration parameters that aid in the interpretation of the physical demands imposed by training, as well as the risk of muscle injury. However, even considering that a representative sample (128 players) was assessed and considering the difficulty of accessing athletes at this competitive level, the collection of more samples per athlete during the various periods would be important for individual monitoring. This fact is important due to the high intra-individual variability in the CK responses to exercise.

Moreover, with an aim to individualize exercise-induced stress monitoring and to protect susceptible athletes from overtraining, Pimenta $^{33}$ evaluated hormonal responses and muscle microtrauma in professional soccer players in relation to genetic variability in the alpha-actinin-3 (ACTN3-577R/X). The players were grouped into the RR, RX, and XX genotypes. The XX group that does not express alpha-actinin-3 showed higher concentrations of CK after a field test of muscle demand than the other groups. Thus, there is a need to adjust the training load based on genetics since it requires different adaptation times for training and muscle recovery.

This study and those that were previously presented, corroborate the ideas of Urhausen and Kindermann ${ }^{34}$, who claimed that CK concentration represents exercise-induced mechanical wear due to the exercise performed in previous days and is linked to training intensity and volume. Hence, for the development of a training program, it is imperative to assess an athlete's muscular stress using indicators, such as $\mathrm{CK}$, considering that the results can guide the type of specific training required for each player in order to prevent overtraining and ensure that the training will improve, or at least maintain, performance.

Therefore, CK can be considered an important tool for monitoring the status and training load of athletes. Furthermore, our results suggest that $\mathrm{CK}$ concentrations expressed in values relative to percentage of the maximum concentration or its maximum delta variation should be individualized and may be more specific for monitoring the training load in team sports, such as soccer.

\section{References}

1. Sporis G, Jukic I \& Milanovic L, Vucetic V. Reliability and factorial validity of agility tests for soccer players. J Strength Conditioning Res. 2010; 24: 679-7.

2. Stolen T, Chamari K, Castagna C \& Wisloff U. Physiology of soccer: An update. Sports Medicine. 2005; 35: 501-35.

3. Coelho DB, Mortimer LA, Condessa LA, Morandi RF, Oliveira BM, Marins JCB, Soares DD \& Silami-Garcia E. Intensity of real competitive soccer matches and differences among player positions. Revista Brasileira de Cineantropometria e Desempenho Humano. 2011; 13: 341-6.

4. Lazarim F, Antunes-Neto J, Silva F, Nunes L, Cameron A, Cameron LC, Alves AA, Brenzikofer R \& De Macedo DV. The upper values of plasma creatine kinase of professional soccer players during the Brazilian National Championship. J Sci Medicine in Sport. 2009; 12: 85-5.

5. Silva JR, Rebelo A, Marques F, Pereira L, Seabra A, Ascensão A \& Magalhães J. Biochemical impact of soccer: an analysis of hormonal, muscle damage, and redox markers during the season. App Physiol, Nutrition and Metabolism. 2014; 39: 432-8.

6. Schmidt GW \& Stein GW. Sport Commitment: A model integrating enjoyment, dropout, and burnout. J Sport Exercise Psychol. 1992; 13: 254-11.

7. Schmidt GW \& Stein GW. Sport Commitment: A model integrating enjoyment, dropout, and burnout. J Sport Exercise Psychol.1992; 13: 254-11.

8. Kane M. Alteration of Immune Function and Muscular Power in College Student Athletes and College Students. J Undergrad Res. 2004; 7: 1-5.

9. Russell M, Northeast J, Atkinson G, Shearer DA, Sparkes W, Cook CJ \& Kilduff L. The between-match variability of peak power output and Creatine Kinase responses to soccer matchplay. J Strength and Conditioning Res. 2015; Jan 26. [Epub ahead of print] 
10. Pultur P, Foster C, Miskowski JA, Kane MK, Burton SE, Scheett TP. Alteration of immune function in women collegiate soccer players and college students. J Sports Sci Medicine. 2004; 3: 234-9.

11. Sari-Sarraf V, Reilly T \& Doran DA. Salivary IgA Response to Intermittent and Continuous Exercise. International J Sports Medicine. 2006; 27: 849-6.

12. Sari-Sarraf V, Reilly T, Doran DA \& Atkinson G. The effects of single and repeated bouts of soccer-specific exercise on salivary IgA. Arch Oral Biol. 2007; 52: 526-6.

13. Ispirlidis I, Fatouros IG, Jamurtas AZ, Nikolaidis MG, Michailidis I, Douroudos I, Margonis K, Chatzinikolaou A, Kalistratos E, Katrabasas I, Alexiou V \& Taxildaris K. Time-course of Changes in Inflammatory and Performance Responses Following a Soccer Game. Clin J Sport Medicine. 2008; 18: 423-8.

14. Zoppi C, Antunes-Neto J, Catanho FO, Goulart LF Motta e Moura N \& Macedo DV. Alterações em biomarcadores de estresse oxidativo, defesa antioxidante e lesão muscular em jogadores de futebol durante uma temporada competitiva. Revista Paulista de Educação Física. 2003;17: 119-21.

15. Clarkson PM \& Hubal MJ. Exercise-induced muscle damage in humans. American J Phys Medicine Rehab. 2007; 81: 52-17.

16. Foschini D, Prestes J \& Charro MA. Relação entre exercício físico, dano muscular e dor muscular de início tardio. Revista Brasileira de Cineantropometria Desempenho Humano. 2007; 9: 101-5.

17. Clarkson PM. Case report of exertional rhabdomyolysis in a 12-year-old boy. Medicine Sci Sports Exercise. 2006; 38: 197-3.

18. Clarkson PM, Kearns AK, Rouzier P, Rubin R \& Thompson PD. Serum creatine kinase levels and renal function measures in exertional muscle damage. Medicine Sci Sports Exercise. 2006; 38: 623-4.

19. Newham DJ, Jones DA \& Edwards RH. Plasma creatine kinase changes after eccentric and concentric contractions. Muscle. 1986; 9: 59-4.

20. Paschalis V, Koutedakis Y, Baltzopoulos V, Mougios V, Jamurtas A Z \& Giakas G. Short vs. Long length of rectus femoris during eccentric exercise in relation to muscle damage in healthy males. Clin Biomechanics. 2005, 20: 617-5.

21. Plebani M. Skeletal muscle biomarkers: not new but still interesting diagnostic tools. Clin Chemistry Lab Medicine. 2010: 48: 745-1.

22. Souglis A, Bogdanis GC, Giannopoulou I, Papadopoulos Ch \& Apostolidis N. Comparison of inflammatory responses and muscle damage indices following a soccer, basketball, volleyball and handball game at an elite competitive level. Res Sports Medicine. 2015; 23: 59-72.

23. Brancaccio P, Maffulli N \& Limongelli FM. Creatine kinase monitoring in sport medicine. Brit Med Bull. 2007; 82: 209-21.

24. Brancaccio P, Maffulli N, Buonauro R \& Limongelli FM. Serum Enzyme Monitoring in Sports Medicine. Clinics in Sports Medicine. 2008; 27: 1-18.

25. Coutts AJ, Reaburn P, Piva TJ \& Rowsell GJ. Monitoring for overreaching in rugby league players. Eur J Appl Physiol. 2007; 99: 313-11.

26. Nunes RT, Andrade FC, Coimbra BD, Nogueira RA, Pinto AF, Filho MGB. Monitoramentos dos efeitos agudos da carga de treinamento no futebol. Revista da Educação Física. 2012; 23:599-7.
27. Clarkson PM \& Ebbeling C. Investigation of serum creatine kinase variability after muscle-damaging exercise. Clin Sci. 1988; 75: 257-4.

28. Heled Y, Bloom MS, Wu TJ, Stephens Q, Deuster PA. CK$\mathrm{MM}$ and ACE genotypes and physiological prediction of the creatine kinase response to exercise. J Appl Physiol (1985). 2007;103(2):504-10.

29. Totsuka M, Nakaji S, Suzuki K, Sugawara K, Sato K. Break point of serum creatine kinase release after endurance exercise. J Appl Physiol.2002; 93:, 1280-6.

30. Antonacci L, Mortimer LA CF, Rodrigues VM, Coelho DB, Soares DD \& Silami-garcia E. Competition, estimated, and test maximum heart rate. J Sports Medicine Physical Fit. 2007; 47: 418 - 421.

31. Alves AL, Silami-Garcia E, Morandi RF, Claudino JG, Pimenta EM \& Soares DD. Individual analysis of creatine kinase concentration in Brazilian elite soccer players. Revista Brasileira de Medicina do Esporte. 2015; 21: 112-116.

32. Cohen J. Statistical Power Analysis for the Behavioral Sciences. (2nd ed.). Hillsdale (NJ): Lawrence Erlbaum Associates, Inc., 1988.

33. Cordova A \& Navas FJ. Os radicais livres e o dano muscular produzido pelo exercício: papel dos antioxidantes. Revista Brasileira de Medicina do Esporte. 2000; 6: 204-4.

34. Pimenta EM, Coelho DB, Cruz IR, Morandi RF, Veneroso CE de Azambuja Pussieldi G, Carvalho MR, Silami-Garcia E \& De Paz Fernández JA. The ACTN3 genotype in soccer players in response to acute eccentric training. Eur J Appl Physiol. 2012; 112: $1495-503$.

35. Urhausen A. \& Kindermann W. Diagnosis of overtraining: What tools do we have? Sports Medicine. 2002; 32: 95-7.

\section{Acknowledgments}

This investigation was supported by CNPq, FAPEMIG, PRPq, CAPES, FINEP, FUNDEP/SANTANDER and Brazilian Ministry of Sport.

We thank to Pro-Reitoria de Pesquisa da Universidade Federal de Minas Gerais (PRPQ-UFMG), CAPES, CNPq e FAPEMIG for their financial support.

\section{Corresponding author}

Emerson Silami-Garcia, Universidade Federal do Maranhão.

Endereço: Av. Dos Portugueses, 1966.

Cidade Universitária - Bacanga.

CEP: 65080-805.

São Luís. Maranhão. Brasil.

Email: emerson_silami@yahoo.com.br

Manuscript received on July 29, 2015

Manuscript accepted on April 19, 2016

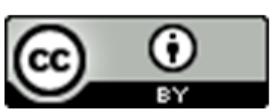

Motriz. The Journal of Physical Education. UNESP. Rio Claro, SP, Brazil - eISSN: 1980-6574 - under a license Creative Commons - Version 3.0 